\title{
Karakterisasi Stabilitas Termal Kaolin Tatakan Kalimantan Selatan
}

\author{
Muhammad Saukani*, ${ }^{1}$ Izzatus Sholehah, ${ }^{2}$ Saifullah Arief, ${ }^{1}$ dan Sadang Husein ${ }^{2}$

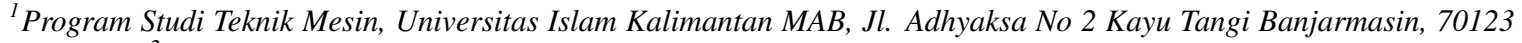 \\ ${ }^{2}$ Program Studi Fisika, Universitas Lambung Mangkurat, Jl. A. Yani Km 36 Banjarbaru, 70712
}

Intisari

\begin{abstract}
Karakterisasi stabilitas termal kaolin Tatakan Kalimatan Selatan telah dilakukan.Penelitian ini bertujuan untuk mempelajari pengaruh termal yang diberikan kepada lempung kaolin untuk penggunaannya sebagai bahan dasar geopolimer.Lempung kaolin yang telah dipreparasi, dikarakterisasi dengan FTIR, DSC-TGA, dan XRD. Hasil analisis DSC-TGA menunjukkan peristiwa predehidroksilasi terjadi pada suhu $50-120^{\circ} \mathrm{C}$, dehidroksilasi terjadi rentang $430-650^{\circ} \mathrm{C}$ dan keadaan paling stabil teramati pada suhu $700-900^{\circ} \mathrm{C}$. Suhu kalsinasi pada lempung kaolin diberikan pada suhu 650,750 , dan $850^{\circ} \mathrm{C}$ dengan waktu tahan 1,3 , dan 5 jam, lempung kalsinasi selanjutnya dikarakterisasi FTIR dan XRD. Hasil FTIR menunjukkan untuk seluruh perlakukan termal telah terbentuk metakaolin yang ditandai hilangnya puncak karakteristik kaolin bilangan gelombang 3600, dan $1600 \mathrm{~cm}^{-1}$. Perlakuan termaldengan suhu $750^{\circ} \mathrm{C}$ dengan waktu tahan 3 jam yang menunjukkan bahwa fasa amorf paling banyak terbentuk yang ditandai dengan terlihatnya penurunan prosentase transmintansi semakin tinggi. Hasil analisis qualitatif dari pola XRD hanya menunjukkan fasa quartz sedangkan fasa kaolinit tidak ditemukan. Hasil ini menunjukkan koherensi dengan hasil FTIR. Perlakuan termal terhadap kaolin tatakan untuk menghasilkan metakaolin reaktif sebagai aplikasi geopolimer dikalsinasi dengan suhu $750^{\circ} \mathrm{C}$ selama 3 jam.
\end{abstract}

\begin{abstract}
This research is to characterize thermal stability of Kaolin from Tatakan, South Borneo. This research have been done by discussing the thermal treatment provided for kaolin clay and it used as a geopolymer base material. The FTIR, DSC-TGA, and XRD characterize the prepared kaolin clay. The DSC-TGA analysis shows that predehydroxylation occurred at temperatures of $50-120^{\circ} \mathrm{C}$. In addition, the dehydroxylation process started at $430-650^{\circ} \mathrm{C}$. However, the most stable condition is at $700-900^{\circ} \mathrm{C}$. Calcination temperature at kaolin clay was given at 650,750 , and $850^{\circ} \mathrm{C}$ with dwell time of 1,3 , and 5 hours. After that, the calcination clay had characterized by FTIR and XRD. The FTIR results showed that all thermal treatments of metakaolin have formed. It was marked by the loss of the characteristic peak of kaolin with wavenumbers of 3600 , and $1600 \mathrm{~cm}^{-1}$. Thermal treatment at a temperature of $750^{\circ} \mathrm{C}$ with a holding time of 3 hours showed the largest amorphous phase formed, which was characterized by a decrease in the highest percentage of transmittance. The crystalline peak of kaolin XRD data at $750^{\circ} \mathrm{C}$ shows that the peak of the crystalline phase of kaolinite was lost. It indicates that metakaolin has formed. Based on the results, it shows that the optimum thermal temperature that given to the kaolin Tatakan to create reactive metakaolin is $750^{\circ} \mathrm{C}$ for 3 hours. Keywords:
\end{abstract}

Keywords: clay; geopolymer;metakaolin; XRD.

*Corresponding author: saukani@uniska-bjm.ac.id

http://dx.doi.org/10.12962/j24604682.v16i1.4756

2460-4682 (C)Departemen Fisika, FSAD-ITS

\section{PENDAHULUAN}

Lempung adalah material dasar yang banyak diminati oleh para peneliti baik dari bidang sains, mineral maupun lingkungan karena karakteristik konduktivitas dan resistansi termalnya $[1,2]$. Lempung kaolin $\left(\mathrm{Al}_{2} \mathrm{O}_{3} .2 \mathrm{SiO}_{2} .2 \mathrm{H}_{2} \mathrm{O}\right)$ salah satu material lempung yang memiliki komposisi hidrous alumunium silikat dengan struktur lapisan 1:1 yang terdiri dari lembaran oktahedral $\mathrm{Al}^{3+}$ sebagai kation oktahedral dan $\mathrm{SiO}_{4}$ sebagai unit dasar [3]. Deposit bahan dasar kaolin di Kalimantan Selatan mencapai 31.123.773 ton, hasil analisis pola
XRD dengan metode Rietveld dihasilkan fasa kaolinit sebesar fasa kaolinit $\mathrm{Al}_{2} \mathrm{Si}_{2} \mathrm{O}_{5}(\mathrm{OH})_{4}$ sebesar 94,6\% [4].

Lempung kaolin banyak dimanfaatkan dalam bidang konstruksi, industri keramik dan bahan kosmetik [5]. Selain aplikasi tersebut lempung kaolin juga dimanfaatkan sebagai bahan dasar geopolimer yang dapat diaplikasikan secara spesifik sebagai material binder pengganti semen portland [6, 7], bata tahan api [8], serta kabin tahan api pada pesawat terbang [9].

Kaolin yang diaplikasikan sebagai bahan geopolymer adalah kaolin yang terdihedroksilasi menjadi metakaolin. Transformasi kaolin menjadi metakaolin dilakukan dengan berbagai suhu dan waktu tahan, tergantung komposisi kimia 


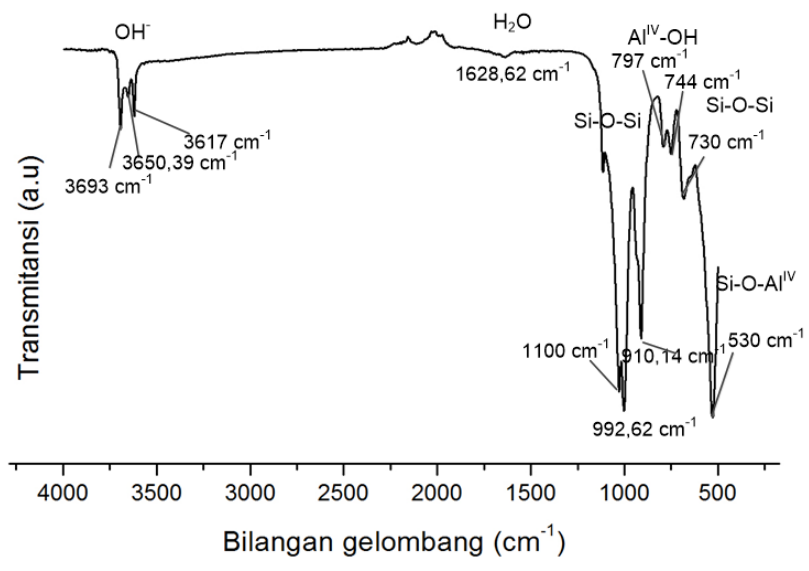

Gambar 1: Spektra FTIR kaolin tatakan.

yang terkandung dalam lempung kaolin. Perlakukan termal terhadap kaolin yang telah dilakukan dalam berbagai penelitian diantaranya $800^{\circ} \mathrm{C}$ selama 3 jam [7], $750^{\circ} \mathrm{C}$ selama 1 jam [10], serta $700^{\circ} \mathrm{C}$ selama 10 jam [11] dan 3 jam [12].

Pemanfaatan kaolin di Kalimantan selatan hanya digunakan sebagai bahan tembikar. Agar dapat diaplikasikan sebagai material geopolimer, maka perlu dipelajari terlebih dahulu stabilitas termal dari kaolin. Oleh sebab itu dalam paper ini akan diuraikan tentang hasil pengujian dan interpretasi waktu tahan serta suhu kalsinasi yang akan menghasilkan kaolin reaktif.

\section{METODOLOGI}

Bahan dasar yang digunakan dalam penelitian ini adalah lempung kaolin yang disampling dari daerah Tatakan kabupaten Tapin. Lempung kaolin direndam dalam akuades, dan dibersihkan dari kotoran kemudian dikeringkan pada oven $105^{\circ} \mathrm{C}$ selama 24 jam. Lempung kemudian digerus dan diayak pada ayakan 200 mesh. Lempung kaolin halus dikarakterisasi gugus fungsi dan pola difraksinya, masing-masing menggunakan FTIR dan Difraksi Sinar X. Penentuan suhu kalsinasi sampel didasarkan pada hasil pengujian DSC-TGA. Waktu tahan kalsinasi divariasikan 1, 3, dan 5 jam. Setelah kalsinasi dilakukan pada sampel dengan waktu tahan yang telah ditentukan, sampel selanjutnya dikarakterisasi gugus fungsi dan pola difraksinya.

Stabilitas termal lempung kaolin diamati dengan DSCTGA dengan rentang suhu kamar hingga $1200^{\circ} \mathrm{C}$ dengan laju pemanasan $10^{\circ} \mathrm{C} /$ menit (Linseiss, STA PT 1600). Gugus fungsi sampel kaolin dipelajari dengan FTIR (Simadzu, IRPrestige 21) dengan rentang bilangan gelombang antara $3996-503 \mathrm{~cm}^{-1}$ dengan pergeseran pengukuran $2,03 \mathrm{~cm}^{-1}$. Sedangkan pola difraksi sinar-X dikarakterisasi menggunakan X-Ray Diffraction (XRD-Philips XPert, rentang sudut $2 \theta=$ $10-65^{\circ}$ dengan pergeseran setiap 0,02 , panjang gelombang $\mathrm{CuK}_{\alpha} 1,54060 \AA$ ). Analisis kualitatif pola XRD ditentukan menggunakan metode Search-match untuk menentukan fasa yang terkandung dalam sampel pada perangkat lunak XPert

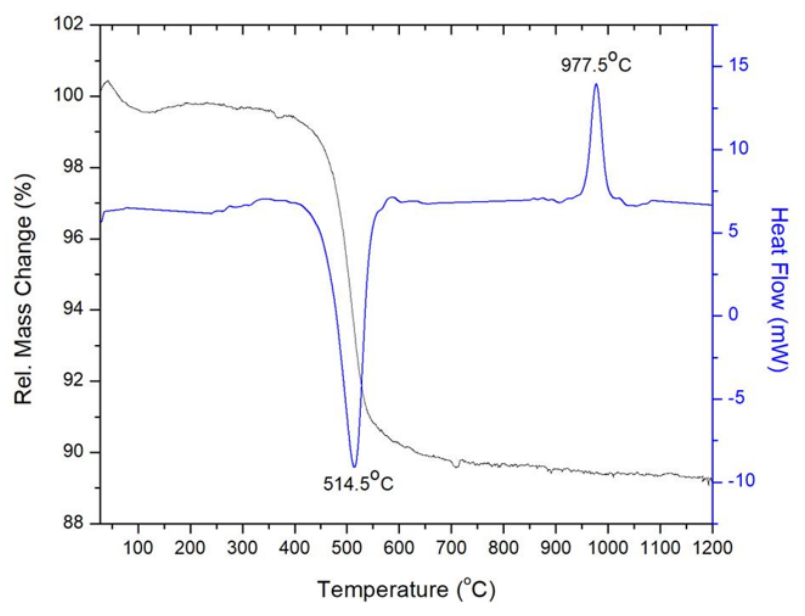

Gambar 2: Hasil pengujian DSC-TGA pada kaolin tatakan.

Highscore Plus.

\section{HASIL DAN PEMBAHASAN}

\section{Karakterisasi lempung kaolin Tatakan}

Gambar 1 adalah spekta pengujian FTIR kaolin tatakan yang telah dipreparasi sebelumnya. Berdasarkan gambar tersebut dapat dilihat bahwa pada bilangan gelombang 3617; 3650,39; dan $3693,30 \mathrm{~cm}^{-1}$ terdapat puncak serapan khas dari kaolin yang berkaitan dengan adanya vibrasi ulur $\mathrm{OH}^{-}$, dan pada bilangan gelombang 1628,62 vibrasi tekuk $\mathrm{OH}^{-}$yang ditunjukkan oleh adanya molekul air pada bilangan-bilangan gelombang tersebut. Pita serapan yang terdapat pada 992,62 $\mathrm{cm}^{-1}$ dan $1100 \mathrm{~cm}^{-1}$ adalah ikatan $\mathrm{Si}-\mathrm{O}$ pada molekul $\mathrm{SiO}_{4}$. Selain itu pada bilangan gelombang $910,14 \mathrm{~cm}^{-1}$ terjadi vibrasi dari $\mathrm{Al}^{I V} \mathrm{OH}$, baru kemudian muncul ikatan tekuk SiO-Si simetris. Puncak serapan tajam lalu nampak pada bilangan gelombang 529 sebagai serapan hasil vibrasi ulur dari $\mathrm{Si}-\mathrm{O}-\mathrm{Al}^{I V}$ dimana pada saat itu $\mathrm{Al}$ dalam keadaan koordinasi oktahedral.

Hasil pengujian stabilitas termal yang ditunjukkan oleh kurva DSC-TGA disajikan pada Gambar 2. Kurva ini DSC (garis berwarna hitam) menunjukkan adanya peristiwa termal yang terjadi pada sampel selama porses pemanasan hingga suhu $1200^{\circ} \mathrm{C}$ yaitu predehroksilasi, endotermik, hidroksilasi, dan eksotermik. Peristiwa predehidroksilasi terjadi pada suhu $50-120^{\circ} \mathrm{C}$, dimana diduga terjadinya evolusi air pada sampel dengan jumlah sedikit. Peristiwa dehidroksilasi terjadi rentang $430-650^{\circ} \mathrm{C}$. Puncak endotermik pada kurva TGA (garis warna biru) tercatat pada suhu $514,5^{\circ} \mathrm{C}$, dimana sampel lebih banyak menyerap panas dari lingkungan yang diikuti dengan adanya pegurangan massa mencapai 9,3\%.Pada keadaan ini kaolin telah mengalami kehilangan kisi $\mathrm{OH}$ pada air sehingga proses dehidroksilasi telah terjadi dengan baik [13]. Reaksi yang terjadi dalam peristiwa ini ditunjukkan sebagai 


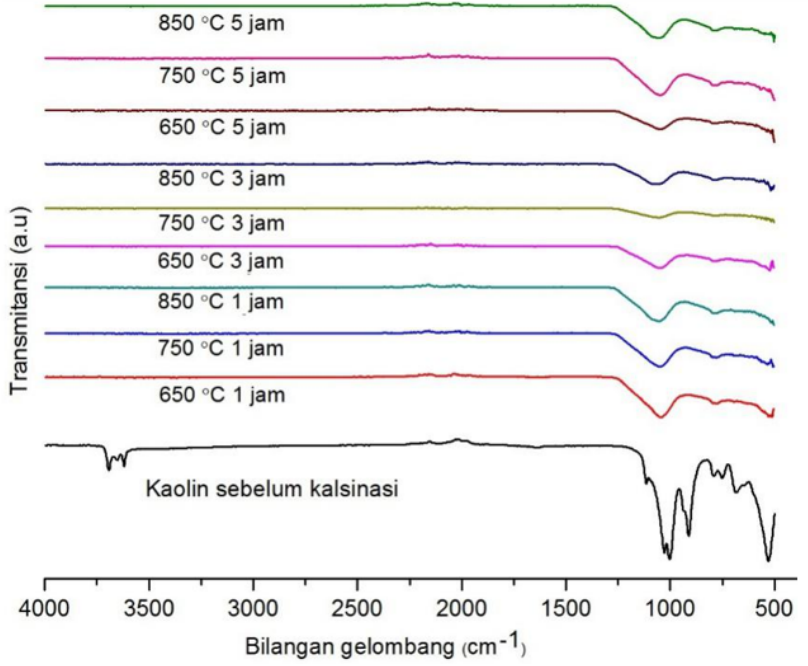

Gambar 3: Spektra FTIR kaolin tatakan dan kaolin yang telah dikalsinasi dengan berbagai suhu dan waktu tahan.

berikut [10]:

$$
\begin{aligned}
& \mathrm{Al}_{2} \mathrm{O}_{3} .2 \mathrm{SiO}_{2} .2 \mathrm{H}_{2} \mathrm{O}(\mathrm{s}) \rightarrow \mathrm{Al}_{2} \mathrm{O}_{3} .2 \mathrm{SiO}_{2}(s)+2 \mathrm{H}_{2} \mathrm{O}(\mathrm{g}) \\
& \text { Kaolinit Metakaolin air }
\end{aligned}
$$

Peristiwa dehidroksilasi menghasilkan perubahan fasa kristalin kaolin $\left(\mathrm{SiO}_{2} \cdot 2 \mathrm{Al}_{2} \mathrm{O}_{3} \cdot 2 \mathrm{H}_{2} \mathrm{O}\right)$ menjadi metakaolin $\left(\mathrm{SiO}_{2} .2 \mathrm{Al}_{2} \mathrm{O}_{3}\right)$ amorf. Peristiwa eksotermik terjadi pada rentang suhu $925^{\circ} \mathrm{C}$ hingga $1100^{\circ} \mathrm{C}$, dan puncaknya terjadi pada suhu $977,5^{\circ} \mathrm{C}$ dimana dalam peristiwa ini akan terbentuk kembali fasa kristalin seperti spinel dan silica amorf [14]. Keadaan paling stabil teramati berdasarkan kurva DSC-TGA adalah antara rentang suhu $700-900^{\circ} \mathrm{C}$, untuk itu suhu kalsinasi diputuskan pada rentang suhu tersebut dan akan dipelajari efek apa yang akan terjadi.

\section{Perlakuan termal}

Penentuan suhu kalsinasi ditentukan berdasarkan kurva DSC/TGA yaitu dengan mempertimbangkan kestabilan kurva maka suhu kalsinasi yang diberikan kepada kaolin adalah 650, 750 , dan $850^{\circ} \mathrm{C}$. Gambar 3 merupakan gambaran keadaan jika kaolin tatakan diberikan perlakuan panas 0 jam dengan jumlah sampel yang sedikit. Oleh sebab itu dengan jumlah sampel yang dikalsinasi sebanyak $30 \mathrm{ml}$ tiap krusible maka dilakukan variasi waktu tahan $1 \mathrm{jam}, 3 \mathrm{jam}$ dan $5 \mathrm{jam}$. Hasil pengujian ini akan dikarakterisasi kembali dengan FTIR dan XRD.

Gambar 3 adalah spektra FTIR kaolin alam dan hasil kalsinasi dengan berbagai suhu dan waktu tahan. Variasi suhu yang diberikan adalah 650,750 , dan $850^{\circ} \mathrm{C}$ dan waktu tahan pemanasan selama 1,3 , dan $5 \mathrm{jam}$. Terlihat adanya kemiripan pola spektra FTIR dari keseluruhan perlakuan panas berdasarkan bilangan gelombangnya. Namun, perbedaan hanya ditunjukkan pada prosentase transmitansi masing-masing sampel. Adanya pemanasan ini menyebabkan kaolin kehilangan puncak-puncak khasnya pada bilangan gelombang 3617; 3650,39; 3693,30; dan 1628,62 $\mathrm{cm}^{-1}$.

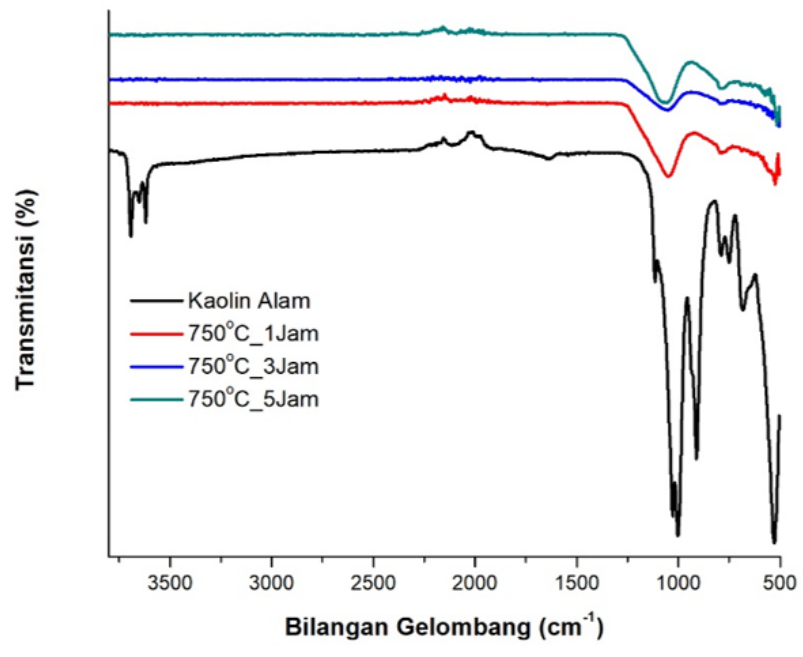

Gambar 4: Perbandingan Spektra FTIR (a) kaolin tatakan sebelum kalsinasi dan (b) kaolin tatakan yang dikasinasi pada suhu 750C dengan waktu tahan 1, 3 dan 5 jam.

Fenomena tersebut menunjukkan bahwa variasi suhu dan waktu tahan yang diberikan mampu mentransformasikan kaolin menjadi metakaolin. Selain itu, pita serapan yang terdapat pada bilangan gelombang $1100 \mathrm{~cm}^{-1}$ mengalami pengurangan menjadi $1031 \mathrm{~cm}^{-1}$ yang merupakan wilayah serapan untuk $\mathrm{SiO}_{2}$ amorf [15].

Pergeseran bilangan gelombang pada spektra FTIR menunjukkan adanya penurunan kurva yang tajam terjadi pada suhu $750^{\circ} \mathrm{C}$ jika dibandingkan dengan variasi kalsinasi lainnya. Waktu tahan pemanasan 3 jam menunjukkan perbedaan yang mencolok jika dibandingkan dengan waktu tahan lainnya. Secara detail pola spektra dengan waktu tahan 3 jam disajikan pada Gambar 4. Pada suhu $750^{\circ} \mathrm{C}$ dengan waktu kalsinasi 3 jam memperlihatkan adanya penurunan tersebut yang kemudian akan semakin menjadi bentuk datar sebelum akhirnya semakin turun, sehingga hal ini menurut Erasmus mengindikasikan adanya peningkatan pembentukan silika amorf selama bertransformasi menjadi fasa spinel yang berbentuk kristalin [16]. Dari hasil FTIR diduga bahwa suhu dan waktu kalsinasi optimum untuk kaolin alam Tatakan adalah pada $750^{\circ} \mathrm{C}$ dengan lama waktu tahan selama 3 jam. Untuk menguatkan pernyataan ini, pengujian XRD dilakukan (pola XRD disajikan pada Gambar 5).

Hasil search-match kaolin alam menunjukkan ada dua fasa yang terbentuk yaitu kaolin $\left(\mathrm{SiO}_{2} \cdot 2 \mathrm{Al}_{2} \mathrm{O}_{3} \cdot 2 \mathrm{H}_{2} \mathrm{O}\right.$, PDF\#00-029-1448) dan Quartz ( $\mathrm{SiO}_{2}$, PDF\#01-085-0505) [4]. Gambar 5 hasil analisis difraksi sinar $\mathrm{X}$ pada material kaolin yang dikalsinasi pada suhu $750^{\circ} \mathrm{C}$ dengan waktu tahan 1, 3, dan 5 jam. Hasil Analisa kualitatif pada pola difraksi ini menunjukkan bahwa dengan suhu kasinasi $750^{\circ} \mathrm{C}$ puncak-puncak kristalin fasa kaolinit pada sudut $2 \theta$ : 19,9; 24,$9 ; 35 ; 36 ; 38,5$; dan $62,4^{\circ}$ telah menghilang. Hilangnya puncak kaolinit ini menunjukkan adanya transformasi kaolin $\left(\mathrm{SiO}_{2} .2 \mathrm{Al}_{2} \mathrm{O}_{3} .2 \mathrm{H}_{2} \mathrm{O}\right)$ berfasa kristal menjadi metakaolin 


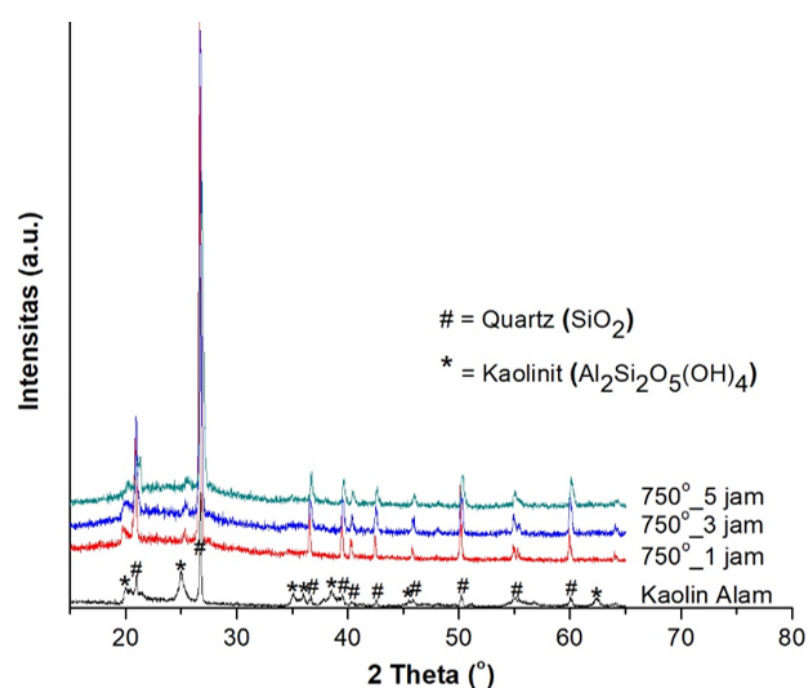

Gambar 5: Pola Difraksi Sinar X kaolin tatakan dan hasil kasinasi $750^{\circ} \mathrm{C}$ dengan waktu tahan.

$\left(\mathrm{SiO}_{2} \cdot 2 \mathrm{Al}_{2} \mathrm{O}_{3}\right)$ berfasa amorf. Hal ini menunjukkan bahwa dengan kalsinasi $750^{\circ} \mathrm{C}$ baik dengan waktu tahan 1,3 , dan 5 jam telah membentuk metakaolin secara sempurna.

\section{SIMPULAN}

Hasil karakterisasi stabilitas termal pada kaolin alam yang berasal dari Tatakan Kalimantan selatan menunjukkan bahwa metakaolin sudah terbentuk pada suhu $650^{\circ} \mathrm{C}$, namun keadaan optimum untuk mendapatkan kaolin dengan derajat amorf yang tinggi metakaolin dikalsinasi pada suhu $750^{\circ} \mathrm{C}$ dengan waktu tahan selama 3 jam.

\section{Ucapan Terima Kasih}

Ucapan terima kasih diberikan kepada Universitas Islam Kalimantan dan Hasnur Riset dan Publikasi (HRP) yang telah memberikan pendanaan dalam pelaksanaan penelitian ini.
[1] C.M.F. Vieira, R. Sanchez, S.N. Monteiro, N. Lalla, and N. Quaranta, "Recycling of electric arc furnace dust into red ceramic", J. Mater. Res. Technol., vol. 2, no. 2, pp. 88-92, Apr. 2013.

[2] M.L. Gualtieri, A.F. Gualtieri, S. Gagliardi, P. Ruffini, R. Ferrari, and M. Hanuskova, "Thermal conductivity of fired clays: Effects of mineralogical and physical properties of the raw materials", Appl. Clay Sci., vol. 49, no. 3, pp. 269-275, Jul. 2010.

[3] M.F. Brigatti, E. Galan, and B.K.G. Theng, "Chapter 2 Structures and Mineralogy of Clay Minerals", in Developments in Clay Science, vol. 1, F. Bergaya, B. K. G. Theng, and G. Lagaly, Eds. Elsevier, pp. 19-86, 2006.

[4] M. Saukani and R. Febrianty, Analisa Komposisi Fasa Lempung Kalimantan Selatan Berdasarkan Data Difraksi Sinar X, J. Fis. FLUX, vol. 13, no. 2, pp. 117-120, Mar. 2017.

[5] H. H. Murray, "Chapter 5 Kaolin Applications", in Developments in Clay Science, vol. 2, H. H. Murray, Ed. Elsevier, pp. 85-109, 2006

[6] F. N. Okoye, J. Durgaprasad, and N. B. Singh, "Mechanical properties of alkali activated flyash/Kaolin based geopolymer concrete", Constr. Build. Mater., vol. 98, pp. 685-691, Nov. 2015.

[7] N. Shafiq, Muhd. F. Nuruddin, S. U. Khan, and T. Ayub, "Calcined kaolin as cement replacing material and its use in high strength concrete", Constr. Build. Mater., vol. 81, pp. 313-323, Apr. 2015.

[8] Nurfadilla, M. Dzulkifli, F. Ramli, and Subaer, "The Potential of Geopolymer as High Quality Refractory”, Mater. Sci. Forum, vol. 841, pp. 21-25, 2016.

[9] R.E. Lyon, P.N. Balaguru, A. Foden, U. Sorathia, J. Davi- dovits, and M. Davidovics, "Fire-resistant aluminosilicate composites", Fire Mater., vol. 21, no. 2, pp. 67-73, Mar. 1997.

[10] M.A. Longhi, E.D. Rodrguez, S.A. Bernal, J.L. Provis, and A.P. Kirchheim, "Valorisation of a kaolin mining waste for the production of geopolymers", J. Clean. Prod., vol. 115, pp. 265-272, Mar. 2016.

[11] K. Hemra and P. Aungkavattana, "Effect of cordierite addition on compressive strength and thermal stability of metakaolin based geopolymer", Adv. Powder Technol., vol. 27, no. 3, pp. 1021-1026, May 2016.

[12] S. Sarkar, S.C. Datta, and D.R. Biswas, "Synthesis and characterization of nanoclaypolymer composites from soil clay with respect to their water-holding capacities and nutrient-release behavior", J. Appl. Polym. Sci., vol. 131, no. 6, 2014.

[13] A. Shvarzman, K. Kovler, G.S. Grader, and G.E. Shter, "The effect of dehydroxylation/amorphization degree on pozzolanic activity of kaolinite", Cem. Concr. Res., vol. 33, no. 3, pp. 405416, Mar. 2003

[14] S. Subagjo, E.S. Rahayu, T. W. Samadhi, and M.L. Gunawan, "Synthesis of NaY Zeolite Using Mixed Calcined Kaolins", J. Eng. Technol. Sci., vol. 47, no. 6, pp. 633-639, Dec. 2015.

[15] Y.M. Liew, H. Kamarudin, A.M. Mustafa Al Bakri, I. Khairul Nizar, C.M. Ruzaidi, and C.Y. Heah, "Processing and characterization of calcined kaolin cement powder", Constr. Build. Mater., vol. 30, pp. 794-802, May 2012.

[16] E. Elizabeth, "The influence of thermal treatment on properties of kaolin", Hemijska industrija, vol. 70, no. 5, pp. 595-601, 2016. 